\title{
CONSTRUINDO UMA HISTÓRIA DE COLABORAÇÃO NA EDUCAÇÃO: A EXPERIÊNCIA DO CEARÁ
}

\author{
SOFIA LERCHE VIEIRA* \\ ELoÍSA MAIA VIDAL ${ }^{* *}$
}

Sendo que aproximar-se

é se afastar.

(Guimarães Rosa)

\begin{abstract}
RESUMO: O artigo trata de formas de colaboração desenvolvidas no campo educacional no estado do Ceará, reconhecido por iniciativas positivas nesta matéria. Para situar o tema, são apresentados elementos do debate atual e considerações sobre a natureza deste processo. A análise focaliza três eixos mutuamente articulados: a colaboração entre o estado e os municípios, por meio de instrumentos de cooperação direta; a colaboração entre estado, municípios e escolas, pela via de organismos regionais de educação; e a colaboração entre escolas, através de incentivos financeiros induzidos pelo governo estadual. Compreendendo a colaboração como processo de mão dupla, argumenta-se e demonstra-se que o pacto cearense foi construído historicamente, sendo alimentado pelo estado e pelos municípios, razão do sucesso da experiência.
\end{abstract}

Palavras-chave: Política educacional. Regime de colaboração. Ceará.

\section{BUILDING A HISTORY OF COLLABORATION IN EDUCATION: THE EXPERIENCE OF CEARÁ}

\begin{abstract}
The article discusses collaboration initiatives developed in education in the state of Ceará (Brazil), which has been recognized for its positive experience in this area. In order to frame the subject into its context a few elements of its current debate are presented as well as some considerations on the nature of the collaboration process. The analysis focuses three mutually articulated issues: the collaboration at the state and municipal levels, through direct mechanisms of cooperation, the collaboration at the state, municipal and school levels through regional institutions and the collaboration among
\end{abstract}

* Universidade da Integração Internacional da Lusofonia Afro-Brasileira (Unilab). Redenção (CE) Brasil.

* $\quad$ Centro de Ciências e Tecnologia da Universidade Estadual do Ceará (Uece). Fortaleza (CE) - Brasil Contato com as autoras: <sofialerche@gmail.com> 
schools, through financial incentives promoted by the state. Understanding collaboration as a two-way process, the central argument is that the collaboration agreement in Ceará has been historically built, being stimulated by both the state and the municipalities throughout time and that is why the experience has been successful.

Key words: Educational policy. Collaboration forms. Ceará.

\section{Construire une histoire de COLlaboration EN MATIÈre D'ÉDUCATION: L'EXPÉRIENCE DE L'ETAT DE CEARA}

RÉSUMÉ: L'article aborde des formes de collaboration développées dans le domaine de l'éducation dans l'état de Ceará, l'un des états du Brésil, qui est connu pour le développement d'initiatives positives dans ce domaine. Pour placer la problématique dans son contexte, des éléments du débat actuel et des considérations sur la nature de ce processus sont présentés. L'analyse se concentre sur trois axes mutuellement articulés: la collaboration entre l'Etat et les municipalités, à travers différents instruments de coopération directe; la collaboration entre l'État, les municipalités et les écoles, par l'intermédiation des agences régionales d'éducation; et, de la collaboration entre les écoles, par des incitations financières mises en œuvre par le gouvernement de l'État. Pour comprendre la collaboration en tant que processus à double sens, il est soutenu et démontré que le pacte de Ceara a été construit historiquement alimenté par l'État puis également par les municipalités au fil du temps, et ceci en raison du succès de l'expérience.

Mots-clés: Politique scolarire. Système de collaboration. Ceará.

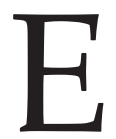

ste texto discute a experiência cearense de colaboração ${ }^{1}$ no campo educacional. Para situar o problema em seu contexto, apresenta-se elementos do debate atual acerca da matéria e algumas considerações sobre a natureza do referido processo. O tema é compreendido como processo que integra três eixos mutuamente articulados, a saber: a colaboração entre o estado e os municípios, através de instrumentos diversos de cooperação direta; a colaboração entre estado, municípios e escolas, pela via de organismos regionais de educação; e a colaboração entre escolas, por meio de incentivos financeiros induzidos pelo governo. Esses três eixos sobre os quais se constroem o(s) modelo(s) de colaboração se efetivam em momentos históricos e políticos distintos, apresentam peculiaridades próprias e têm como suporte as condições financeiras dos entes federados envolvidos.

A epígrafe extraída de Guimarães Rosa sugere um mote para auxiliar a descrever adequadamente o movimento do real, em que, de um lado, é preciso afastar-se para ver melhor; e, de outro, aproximar-se para captar detalhes. $\mathrm{O}$ afastamento requer um recuo no tempo, nele buscando as raízes da colaboração no Ceará, uma vez que esta construção histórica é um dado fecundo para compreender o que tornou possível tal trajetória. Do mesmo modo, a aproximação é um requisito para compreender o que foi 
feito com o legado deixado pelos movimentos anteriores. Nesse sentido, assim como "aproximar-se é se afastar", também afastar-se é se aproximar.

\section{Situando o debate}

A relação entre as esferas governamentais é tema inscrito nas origens da história da educação brasileira. A distribuição de responsabilidades entre as instâncias federativas é anunciada no chamado Ato Adicional de $1834{ }^{2}$ que atribui às Assembleias Legislativas provinciais competência para legislar "sobre instrução pública e estabelecimentos próprios a promovê-la" (art. 10, 2º). Embora incluído na Constituição Federal de 1988 (art. 211), o "regime de colaboração" é remetido à Lei Complementar (parágrafo único, art. 23), sendo regulamentado pela Emenda Constitucional n. 14, de 1996 e referendado pela Lei de Diretrizes e Bases (LDB - Lei n. 9.394, art. 8º ).

Tomando de empréstimo a expressão de Gracindo (1994), pode-se dizer que desde tal definição muito foi escrito, dito e feito sobre a questão. A cooperação entre os governos federal, estaduais e municipais, sem dúvida, teve inequívocos avanços nos 25 anos que nos separam da promulgação da Carta Magna.

A relação entre os entes federados hoje é muito diferente do passado e isto tem a ver com condições políticas, financeiras e de implementação que viabilizaram maior aproximação entre as instâncias do poder público. Condições institucionais foram criadas para assegurar o cumprimento do direito à educação, mediante a introdução e o aperfeiçoamento de mecanismos financeiros de transferências entre a União, estados e municípios. Neste contexto, a União tem procurado responder ao desafio de exercer sua função redistributiva e supletiva (LDB, art. $8^{\circ}, \S 1^{\circ}$ ), contribuindo para a redução das desigualdades em realidades marcadas por flagrantes disparidades regionais e locais.

Mediante um conjunto de modificações legais, alterações profundas foram feitas nos mecanismos de distribuição de recursos para a educação básica, criando novos instrumentos e alterando outros já existentes, caso, por exemplo, do Salário Educação. ${ }^{3}$ Na esteira da LDB é aprovado o Fundo de Manutenção e Desenvolvimento do Ensino Fundamental e de Valorização do Magistério (Fundef - Lei n. 9.424, de 24 de dezembro de 1996), fator de indução de modificações significativas na distribuição da oferta de matrículas entre redes estaduais e municipais em inúmeras unidades da Federação. Cerca de dez anos depois do Fundef, seria criado um novo fundo, de modo a estender para outras etapas da educação básica, recursos já assegurados para o ensino fundamental. Nesse contexto, o Fundo de Manutenção e Desenvolvimento da Educação Básica e de Valorização dos Profissionais da Educação (Fundeb - Lei n. 11.494, de 20 de junho de 2007), ainda que não configurasse como 
instrumento direto do "regime de colaboração", veio a contribuir para explicitar as responsabilidades da União, estados, Distrito Federal e municípios no cumprimento do direito à educação.

Segundo Abrucio (2012, p. 17), o "regime de colaboração" apresentou-se como "ideia perfeita para lidar com a necessidade de conjugação entre autonomia e interdependência dos entes federativos; na prática, porém, mostrou-se 'pouco eficaz'”, contribuindo para inquietações em torno das dificuldades desta relação. Isto é tão verdadeiro que persiste a busca por novas respostas ao desafio da cooperação.

Ao longo dos anos de vigência deste regime, o governo federal criou e implementou iniciativas diversas de estreitamento das relações entre os entes federados que abarcam um amplo espectro de iniciativas, desde os instrumentos financeiros antes aludidos, a programas de fortalecimento da esfera municipal, caso do Plano de Ações Articuladas (PAR), do Programa de Apoio aos Dirigentes Municipais de Educação (Pradime) e do Programa Nacional de Capacitação de Conselheiros Municipais de Educação (Pro-Conselho), ${ }^{4}$ entre outros.

No âmbito normativo, por sua vez, novas alternativas de aproximação foram buscadas. O Conselho Nacional de Educação (CNE) contribuiu para alargar o horizonte dessa discussão, ao estabelecer definições para os Arranjos de Desenvolvimento da Educação (ADE - Resolução n. 1, de 23 de janeiro de 2012); também estes, por sua vez, objeto de polêmica. A ideia subjacente aos referidos "arranjos" articula-se à concepção de alternativas para além das formas de colaboração entre as instâncias federadas asseguradas pela legislação inaugurada em 1988 e detalhada pela Emenda Constitucional n. 14/1996. Colocam-se como possibilidade de oferecer "mecanismos capazes de fortalecer o regime de colaboração não só na esfera vertical (União, estados e municípios) como na horizontal entre municípios, tomando como referência a organização territorial do Estado" (BRASIL, 2011, p. 1). Os ADE foram concebidos com a perspectiva de

[...] trabalhar em rede, onde um grupo de municípios com proximidade geográfica e características sociais e econômicas semelhantes busca trocar experiências e solucionar conjuntamente dificuldades na área da educação, trabalhando de forma articulada com os estados e a União, promovendo e fortalecendo a cultura do planejamento integrado e colaborativo na visão territorial e geopolítica.

A ideia de rede, característica peculiar à organização da vida contemporânea, tem forte potencial agregador no desenvolvimento da educação. Não obstante, os ADE ainda não se disseminaram como prática comum no país. Uma experiência concreta nessa direção é o ADE do noroeste do estado de São Paulo, integrado por 36 municípios do referido estado. ${ }^{5}$ 
Uma crítica aos ADE tem sido a possibilidade de representarem "atalho silencioso do empresariado para a definição e regulamentação do regime de cooperação" (ARAUJO, 2012). Se for verdade que o Parecer do CNE deixou clara possibilidade de inclusão de outros atores sociais além do estado, a possibilidade de transferências de recursos públicos para tais segmentos não estava em suas cogitações, como se vê na passagem a seguir:

Os ADEs, não obstante a forte característica intermunicipal, devem agregar a participação do estado e União, incluindo ou não a participação de instituições privadas e não governamentais, tais como empresas e organizações diversas, que assumem o objetivo comum de contribuir de forma transversal e articulada para o desenvolvimento da educação em determinado território que ultrapassa as lindes de um só município, sem que haja para isso transferência de recursos públicos para tais instituições e organismos privados. (BRASIL, 2011, p. 4)

Dando sequência ao debate sobre a matéria e buscando aprofundar a institucionalização dessa estratégia inovadora, o Ministério da Educação (MEC), por meio de sua Secretaria de Articulação com os Sistemas de Ensino (Sase), "constitui um Grupo de Trabalho para elaborar estudos sobre a implementação de regime de colaboração mediante Arranjos de Desenvolvimento da Educação" (Portaria n. 1.238, de 11 de outubro de 2012). Para tanto, o Grupo realizou encontros diversos com especialistas e representantes de órgãos de governo, visando aprofundar a perspectiva de um "sistema nacional de educação e territórios de cooperação educacional". ${ }^{6}$

As duas expressões cunhadas no debate recente - "arranjos de desenvolvimento da educação" e "territórios de cooperação educacional" - sugerem a possibilidade de desenhos distintos daqueles antecipados para o "regime de colaboração" quando de sua inserção no capítulo da Educação da Constituição de 1988. Tais configurações, a propósito, estão previstas no novo Plano Nacional de Educação $(\mathrm{PNE})^{7}$ e procuram incorporar uma diversidade de experiências que tem surgido no país com a participação de atores não vinculados às instâncias do Executivo (União, estados e municípios). Tais iniciativas projetam luz sobre outros espaços/territórios por onde a articulação pode e deve ocorrer.

Por muito tempo a questão do território foi tema pouco presente no debate da política educacional brasileira. Em cenário recente, todavia, passou a ser compreendido como tema estratégico, emergindo como desafio teórico e prático na formulação de políticas e de estudos direcionados para o enfrentamento dos grandes desafios neste campo. Os estudos sobre a sociologia das desigualdades escolares (AYED, 2012) não têm se furtado a esta discussão e emergem como uma rica possibilidade de aproximação aos problemas educacionais em grandes metrópoles, como têm mostrado algumas pesquisas recentes sobre a matéria também no Brasil (KOSLINSKI; ALVES, 2012; CENPEC, 2011, entre outros). 
É neste contexto mais amplo que se coloca a presente reflexão sobre o regime de colaboração no Ceará, uma das unidades da Federação que costuma ser reconhecida por uma experiência positiva em relação à articulação entre estado e municípios. Tendo uma das autoras escrito sobre o tema (VIEIRA, 2010) e compartilhado experiências na gestão do sistema estadual de educação, ocorreu-nos começar retomando a brincalhona epígrafe utilizada no referido texto de que sapo não pula por boniteza, mas porém, por precisão (GUIMARÃES ROSA, 1994, p. 429).

O "proverbio capiau" do grande mineiro instiga a reflexão: por que o sapo criatura a quem, no imaginário popular, foi barrado até mesmo o acesso ao céu -, em vez de se arrastar, como outros répteis, pula? Seríamos nós, cearenses, os únicos "sapos" que, por precisão, pulamos = colaboramos? Certamente, não. Mas a imagem de um secretário municipal de Educação do interior do Piauí, ${ }^{8}$ afirmando "ter inveja" da experiência do Ceará, me estimulou a contar... Por onde foi que as coisas começaram? O que foi feito para assegurar a sustentabilidade das iniciativas de cooperação?

Refletindo sobre o caminho percorrido, procuramos localizar fatores que poderiam ter contribuído para a configuração do desenho que hoje se apresenta. Este ensaio procura refletir sobre algumas iniciativas que fizeram diferença neste longo percurso de aproximação. Algumas considerações sobre o entendimento da colaboração como processo e produto, porém, são oportunas antes de ingressar nos três eixos da análise.

\section{Colaboração - processo e produto}

Talvez seja oportuno iniciar pelo reconhecimento de que, como qualquer empreendimento humano, a colaboração é uma construção histórica, cujo sucesso implica confiança e cooperação mútuas. Cada Unidade da Federação tem uma narrativa própria a respeito da trajetória empreendida para chegar ao atual desenho de seu(s) sistema(s) de ensino. O simples fato de um sistema ser mais ou menos municipalizado, por si, não é indicador de colaboração, vez que a(s) história(s) é(são) produto de diferentes contextos. Com isso se quer dizer que o território, com efeito, é elemento central na definição das diferentes formas de organização, visando o desenvolvimento da educação. As Unidades da Federação identificadas como experiências positivas de colaboração, caso do Rio Grande do Sul, Mato Grosso e Ceará (OLIVEIRA; SANTANA, 2010), têm percursos diferenciados. Estes se articulam a relações que se estabelecem no âmbito territorial e estão associados às condições de reprodução da vida material no espaço humano.

É de se supor que, em alguns estados, o regime de colaboração seja tributário de decisões do "centro para a periferia" - ou seja, há de ter havido iniciativas onde o estado deliberou o que deveria ser feito e os municípios acataram. Em outros, a 
negociação pode ter sido conduzida em um ambiente colaborativo, e tudo isto expressa as diferentes histórias antes referidas. No Ceará, a municipalização foi buscada ao longo do tempo e em permanente processo de aproximação e negociação entre o governo estadual e os governos municipais.

Embora no caso da relação estado(s)-município(s) se tenda a associar colaboração à municipalização do ensino, esta, por si, não sinaliza a existência de um processo de tal natureza. Apesar dos dados da oferta pública de ensino fundamental ${ }^{9}$ expressarem grandes diferenças existentes entre os estados, obviamente ocultam os mecanismos que geraram tal situação. Números recentes (BRASIL, 2011) mostram que, de uma maneira geral, a maior participação municipal ocorre no Nordeste com situações extremas como no Maranhão $(79,0 \%)$ e no Ceará $(76,6 \%)$. Outros estados, entretanto, ostentam dados aproximados aos das demais regiões e do país, a exemplo de Pernambuco (57,7\%), Rio Grande do Norte (56,8\%), Paraíba (56,3\%) e Sergipe (55,3\%). O Ceará é um caso de alta municipalização feita de forma colaborativa. Rio Grande do Sul (47,6\%) e Mato Grosso (46,9\%), citados como exemplos de colaboração, por sua vez, estão abaixo da média de oferta municipal do Brasil, que é de $54,4 \%$. Os números, portanto, não oferecem indicações precisas de que municipalização equivale a forte colaboração, ou vice-versa.

A história de colaboração no Ceará se articula a um caminho mais amplo e mais largo percorrido na direção do enfrentamento de condições de pobreza quase endêmica do estado. É importante lembrar que algumas iniciativas exemplares nasceram neste estado, caso dos agentes comunitários de saúde. Essa experiência iniciou-se no pequeno município de Jucás, no primeiro governo de Tasso Jereissati, na década de 1980 e, posteriormente, foi incorporada ao sistema estadual de saúde e adotada em outras Unidades da Federação. Nesse sentido é oportuno reconhecer que a cooperação é também uma cultura para a qual contribuem fatores diversos. $\mathrm{O}$ espírito solidário que se expressa em gestos como oferecer água a quem tem sede, abrigo ao viajante que passa, somando-se a uma dose de empreendedorismo inscrito no código genético cearense, pode, por sua vez, ter adicionado elementos diferenciadores importantes no percurso que vem sendo feito por esta Unidade da Federação.

Para o sucesso das iniciativas de colaboração, é indispensável que as várias esferas de governo atuem em sintonia e esta é uma empreitada complexa. Interesses de várias ordens se cruzam e se superpõem umas às outras, correndo o risco de inviabilizá-las. Além de vontade política, demanda paciência e disposição legítima para trabalhar junto. Requer, por outro lado, a instauração de mecanismos que preencham espaços existentes para além da relação direta entre as três esferas. É precisamente nesta interseção que a dimensão territorial ganha relevância, como tem mostrado a experiência dos consórcios públicos, criados em várias regiões do país (Lei n. 11.107/2005). 
Outro aspecto importante da colaboração diz respeito ao elemento de continuidade, por vezes tão ameaçado, quando ocorrem mudanças nas diferentes esferas de governo. Neste contexto, se faz oportuno aprofundar como e por que, ao longo de distintos governos e com políticas e prioridades diversas, uma experiência de tal natureza tenha se constituído como permanência. Se governadores, prefeitos e secretários mudaram, equipes técnicas permaneceram. Se a uns coube o gesto desbravador de delinear rumos, a outros, a tarefa cotidiana de organizar rotas. Importa que, ao fim e ao cabo, a empreitada foi de todos. Dito em poucas palavras e analisando-se o resultado a partir do que se vê hoje, o processo pode até parecer simples, mas não foi; nem é.

\section{Mecanismos de articulação}

A colaboração, tal como concebida pela Constituição de 1988 (arts. 22, 23, 24, 30 e 211) e referendada pela LDB de 1996 (art. 8º é um mecanismo de articulação vertical entre os três entes federados - a União, os estados e os municípios - em que distintas incumbências são atribuídas a cada uma dessas instâncias do poder público (LDB, art. 8o , 9o , 10, 11). Posto de tal maneira, trata-se de uma cooperação em que o mais forte dispõe sobre a colaboração com o menos forte, não havendo grande margem de inovação para uma ou outra parte. Aos municípios sequer é prevista a incumbência de conceber políticas próprias de educação. A despeito dos dispositivos legais, é preciso ter em mente que "cooperar" e "colaborar" são verbos que supõem dupla direção - colaboramos em conjunto, uns com os outros - eu te ajudo, tu me ajudas, nós nos ajudamos. Há, portanto, considerável margem de inovação tanto na verticalidade, quanto na horizontalidade a ser explorada pelos entes federados.

Observando-se a relação União-estados-municípios em matéria de educação, numa perspectiva de seu produto, não deixa de surpreender a tendência do poder central de eleger como prioridade a colaboração direta com municípios e escolas. Em tais circunstâncias, a instância estadual não raro se apresenta como uma grande esquecida pelo regime de colaboração alimentado pelo governo federal. Por isso mesmo, talvez, alguns estados tenham exercido protagonismo em cultivar outra via, o que, sem dúvida, relaciona-se a contextos de influência política e especificidades próprias de cada Unidade da Federação. Pensando em termos do Ceará, algumas características orientaram esta aproximação.

\section{Colaboração entre estado e municípios}

Considerando uma trajetória descrita e já referida no presente ensaio (VIEIRA, op. cit.), é oportuno registrar que, embora tenha se fortalecido a partir do Fundef, o compartilhamento de responsabilidades na oferta de educação no Ceará é 
muito anterior à Constituição de 1988. Veras (1990, p. 216) identifica forte participação dos municípios na oferta de ensino fundamental já no início da década de 60 do século $X X$, quando estes respondiam por $52,1 \%$ da matrícula e o estado por $33,3 \%$. O dado não é trivial e os percentuais apontam uma tendência que se consolida ao longo do tempo. Em um contexto de escassez de recursos, em que a parte mais fraca - os municípios - respondia por um volume muito mais expressivo de matrículas que a parte mais forte - o estado -, a cooperação parecia mostrar-se como um caminho natural.

Entre outras iniciativas, em 1977, foi criado o Projeto de Assistência Técnica aos Municípios (Pro-Município), que, para Mendes (2002), constitui a primeira iniciativa de municipalização do ensino fundamental no Ceará (VIEIRA, op. cit.). Em 1989, a Constituição Estadual (CE) dispôs sobre uma aproximação que na prática, desde há muito, vinha em andamento: a cooperação técnica entre o estado e os municípios, ao definir que "O Estado prestará assistência técnica e financeira aos municípios que mantenham o ensino fundamental, devendo decretar a medida de intervenção, ao verificar não haver sido aplicado o mínimo exigido da receita municipal (art. 227, § $\left.1^{\circ}\right)^{\prime \prime}$.

Com o caminho aberto e estimulado pela Constituição Federal de 1988 e referendado pela Constituição Estadual de 1989, seguem-se as duas outras iniciativas de municipalização: a primeira delas, instituída por Decreto em 1990 (n. 20.620/1990), é relativamente frustrada; a segunda, em 1995 (Lei n. 12.452/1995), ocorreu em momento de terreno propício para um passo de tal envergadura.

Sob a vigência da lei de municipalização do ensino público do Ceará, é possível identificar três etapas distintas na construção do processo de colaboração entre o estado e os municípios, correspondentes aos governos de Tasso Jereissati (19952002), Lúcio Alcântara (2003-2006) e Cid Gomes (2007-2013). Aqui dois aspectos são importantes: o contexto mais amplo de cada uma dessas administrações, que se diferenciam entre si por fatores de ordem política e financeira, bem como a continuidade da experiência de colaboração que se manteve como um vetor central da política estadual por um longo intervalo de tempo. ${ }^{10}$ As sementes plantadas nos dois primeiros momentos puderam, então, vicejar em plenitude no terceiro momento. É possível que tal continuidade não seja percebida nem reconhecida pelos formuladores e executores de políticas do presente, para quem o hoje representa um rompimento com o passado. Tais representações, que fazem parte do ir e vir da gestão pública, talvez venham a ser resignificadas pelo tempo.

A instituição do regime de colaboração se materializou a partir do início do segundo governo de Jereissati (1995-2002), tendo a continuidade desta gestão por oito anos sido decisiva para a irreversibilidade do processo. Conforme referido, a municipalização foi institucionalizada por meio de lei específica e da celebração de 
convênios que envolveram a transferência de recursos do estado para os municípios. Inicialmente, através de experiência piloto em alguns municípios e, depois, ampliada para o conjunto, a municipalização envolveu massiva transferência de matrículas, cessão de professores e prédios, resultando em rápida mudança no perfil da oferta de ensino fundamental. ${ }^{11}$

O Fundef representou um caminho fecundo para acelerar tal processo. Em um quadro de escassez de recursos, a ideia de um per capita por aluno exerceu forte apelo sobre os municípios. A decisão do governo estadual de transferência das responsabilidades na oferta do ensino fundamental resultou em um processo onde os municípios assumiram os encargos pela matrícula ${ }^{12}$ e o estado repassou não apenas recursos financeiros como também pessoal, instalações, equipamentos, entre outros. E tudo isso foi feito sem maiores preocupações com a formalização de acordos. Passada essa fase inicial, uma fase de organização do pacto colaborativo se fez necessária, etapa que ocorreu na gestão subsequente, sob o governo Alcântara (2003-2006).

Este segundo momento do pacto colaborativo coincidiu com um contexto peculiar na administração estadual, situação comum a outros estados do Nordeste. As transferências dos recursos do Fundef aos municípios praticamente consumiam o orçamento do estado, que passou a enfrentar a falta de recursos próprios para fazer face ao vertiginoso crescimento das matrículas de ensino médio. Sem uma contrapartida em termos de novas fontes de recursos, como outros estados do Nordeste, o Ceará recebeu recursos emergenciais da União para honrar compromissos básicos de custeio da máquina educacional.

A despeito das dificuldades financeiras próprias do período, a municipalização se constituiu um caminho sem volta. Mantidas as transferências de recursos do estado para os municípios pela via do Fundef, outras formas de colaboração foram ensaiadas. Ao lado da formalização de acordos, nem sempre simples, ampliou-se a cooperação técnica, em várias frentes de atuação. Recursos de um projeto do Banco Mundial, elaborado e iniciado pela gestão anterior, permitiram pagar custos elevados de formação de professores e de gestores estaduais e municipais. Ao lado disso, projetos diversos de ampliação e melhoria da rede física dos municípios foram realizados e foram desenvolvidas iniciativas com vistas à equidade do atendimento educacional dos municípios com menor Índice de Desenvolvimento Humano (IDH). O diálogo entre o estado e os municípios ampliou-se e fortaleceu-se e, com isso, foi possível caminhar no sentido da construção de uma cultura de avaliação das redes escolares, de uma gestão integrada da escola e de apoio à elaboração de planos municipais de educação, entre outros.

A saúde financeira do estado veio a vivenciar período menos adverso quando a União passou a exercer sua função redistributiva de forma mais plena e não mais em caráter pontual e emergencial. Isto só ocorreu sob a vigência de um novo governo, 
em 2007, e já com a criação do Fundeb, quando se deu a fase de fortalecimento do pacto colaborativo, sob o governo Gomes (2007-atual). A experiência de alfabetização na idade certa, iniciada em Sobral, foi escolhida como a prioridade da nova gestão, generalizando-se para todos os municípios do estado sob a denominação de Programa Alfabetização na Idade Certa (Paic). A experiência municipalista de que era portadora a nova gestão da Secretaria de Educação do estado favoreceu o fortalecimento das iniciativas de colaboração. Com isso, um amplo programa de cooperação se deu em várias direções, incluindo a formação de professores e a presença de um técnico em cada secretaria municipal para acompanhar o andamento do Paic. O cenário financeiro, com a implantação do Fundeb, criou condições favoráveis para a ampliação de parcerias envolvendo repasse de recursos aos municípios. Além disso, o estado criou diversos mecanismos de indução no sentido de orquestrar a melhoria da qualidade da oferta municipal, entre eles uma lei que vincula o repasse de recursos ao desempenho escolar de alunos das redes municipais, ${ }^{13}$ assim como prêmios significativos associados ao desempenho escolar.

Analisando o caminho percorrido no processo de aproximação entre os dois entes federados - estado e municípios -, pode-se afirmar que este foi um percurso buscado e cultivado por ambas as partes. Embora nem sempre simples, a confiança mútua permitiu que acordos os mais diversos fossem firmados e tal atitude foi essencial para a consolidação da experiência cearense de colaboração. Muito antes dos ônibus amarelinhos, adquiridos com recursos do Fundo Nacional de Desenvolvimento da Educação (FNDE), trilharem as estradas do sertão, serra e litoral, estudantes das duas redes eram transportados mediante acordos celebrados entre o estado e as prefeituras. Uma rede de colaboração espontânea e invisível marcou este itinerário. E tudo isso foi facilitado pela modalidade de cooperação a ser descrita no próximo tópico, referente ao papel das instâncias regionais de educação no processo.

\section{Colaboração entre estado, municípios e escolas pela via de organismos regionais}

A presença de alguma forma de organização territorial na gestão das responsabilidades do estado na oferta de educação pública é antiga. Suas origens podem estar associadas aos serviços de inspeção escolar referidos pela legislação educacional desde o século XIX. No caso do Ceará, a existência material de tais organismos remonta às antigas Delegacias Regionais de Educação (Dere), cuja construção no Ceará foi viabilizada com recursos do governo federal.

É oportuno lembrar que os diferentes formatos regionais admitidos pelo Instituto Brasileiro de Geografia e Estatística (IBGE), ou existentes nas distintas áreas de atuação dos governos estaduais, costumam ser uma presença constante na administração 
pública. Não raro, o desenho das microrregiões estabelecidas pelos órgãos de planejamento não coincide com os de saúde, de educação, de infraestrutura, entre outros. Tais superposições podem representar duplicação de esforços, em flagrante descompasso com os princípios da administração pública.

Seja como for, guardadas as peculiaridades de cada estado, é importante assinalar que os diferentes agrupamentos regionais perseguem uma atuação em sintonia com a identidade territorial. Considerando a "vastidão do espaço geográfico" brasileiro (BACELAR, 2008a, p. 1) e as peculiaridades das regiões, tal distribuição importa e faz diferença. Como outros estados da Federação, o Ceará, misto de serra, sertão e litoral, com 86,8\% de solo semiárido (RIBEIRO; SILVA, 2010), tem muitas faces e diferentes problemas. As regiões, como "construções sociais" nos territórios (BACELAR, 2008b, p. 16), têm sido um componente positivo da experiência de colaboração desenvolvida no estado.

O fortalecimento de órgãos regionais de educação foi um mecanismo intencionalmente perseguido pelo governo estadual para facilitar a cooperação e que se revelou eficaz na conquista de avanços, em termos de ampliação do acesso e da melhoria da qualidade. Esta construção remonta a meados dos anos de 1990, quando os órgãos regionais de educação foram restruturados e fortalecidos, vindo a desempenhar função estratégica na mediação entre o estado e os municípios, assim como na gestão das escolas da rede estadual.

A transformação das antigas Dere em centros - posteriormente, Coordenadorias Regionais de Desenvolvimento da Educação (Crede) - não se limitou a uma mera troca de nomenclatura dos órgãos. Os centros/coordenadorias foram redimensionados visando melhor sintonia com as especificidades de cada região. Seus dirigentes, antes escolhidos por indicação política, passaram a ser selecionados publicamente. A referida mudança não se restringiu a ajustes estruturais e alteração dos critérios de acesso a cargos de liderança. Antes, correspondeu a importante e necessária renovação que veio a resultar em uma rede de comunicação e apoio mútuo entre o estado e os municípios, contribuindo de forma decisiva para ativar a capilaridade do sistema escolar na busca de soluções conjuntas para problemas comuns.

Exercendo atribuições específicas no desenho do pacto colaborativo no Ceará, as Crede operacionalizam as políticas estaduais e contribuem para sua chegada à ponta do sistema. Instâncias mediadoras entre o estado, municípios e escolas desempenham papel ímpar no respeito às especificidades regionais no desafio educacional.

\section{Colaboração entre escolas}

Considerando a trajetória mencionada, a cooperação entre escolas apresenta-se como um mecanismo de aproximação natural e peculiar ao Ceará. A esta colaboração 
espontânea, acionada na solução de problemas comuns do cotidiano, veio a somar-se outra modalidade induzida pelo governo estadual, sob a vigência do Paic, através do Prêmio Escola Nota Dez. Instituída em 2009 (Lei n. 14.371/2009) e reformulada em 2011 (Lei n. 15.052/2011), a premiação destina recursos às 150 escolas

[...] que tenham obtido os melhores resultados de alfabetização, expressos pelo Índice de Desempenho Escolar-Alfabetização (IDE-Alfa), e as escolas públicas que tenham obtido os melhores resultados do $5^{\underline{o}}$ ano, expressos pelo Índice de Desempenho Escolar $-5^{\underline{o}}$ ano (IDE 5). (Art. $1^{\circ}$ )

\section{São também}

[...] beneficiadas com contribuições financeiras, em igual número ao das premiadas, as escolas públicas que obtiverem os menores resultados nas avaliações do Spaece de $2^{\underline{0}}$ e $5^{\circ}$ anos do ensino fundamental, expressos pelo IDE-Alfa e IDE-5, para implementação de plano de melhoria dos resultados de aprendizagem de seus alunos. (Art. $5^{\circ}$ )

Para que as escolas com melhores e piores resultados sejam beneficiadas, é necessário que estas cooperem entre si:

As escolas premiadas e as contempladas com contribuição financeira ficam obrigadas a desenvolver, em parceria, pelo período de até dois anos, ações de cooperação técnicopedagógica com o objetivo de manter ou melhorar os resultados de aprendizagem de seus alunos. (Art. $\left.7^{\circ}\right)$

Segundo formuladores desta política estadual, de uma maneira geral, tal mecanismo de cooperação tem sido positivo, embora existam focos isolados de resistência de parte a parte, de modo especial pelas escolas com resultados mais baixos. A Pesquisa de boas práticas 2011 (SEDUC, s./d.) dedica um capítulo à análise mais detalhada desta cooperação técnico-pedagógica em uma amostra de oito pares de escolas (escola premiada/escola apoiada), e constata que o conjunto de iniciativas desenvolvidas pelas escolas premiadas teve o objetivo comum de "compartilhar experiências, transferindo conhecimentos e práticas pedagógicas que contribuíram para que as escolas apoiadas tivessem um bom desempenho no Spaece-2010" (SEDUC, s./d. p. 215). Estas foram

[...] pautadas por um mesmo norte: o pragmatismo das ações de cooperação claramente direcionadas de forma objetiva e certeira à superação das fragilidades apresentadas pelos alunos do segundo ano das escolas apoiadas. Este elemento refere-se a um conjunto de ações que estão direcionadas para que a escola implante estratégias pedagógicas, objetivando resultados concretos e imediatistas, na aferição dos níveis de desempenho escolar nas avaliações externas.

Verificou-se que as principais ações de cooperação técnico-pedagógica, realizadas por estas oito escolas de ensino fundamental das redes municipais contempladas 
com o prêmio Escola Nota 10 (edição 2010) nas escolas apoiadas, focalizaram: reforço escolar (88\%), avaliação por descritores e simulado (50\%) e metodologia e práticas de ensino ativas (100\%) (ibid., p. 216).

A alternativa de estimular bons resultados, sem perder o foco sobre a melhoria das escolas em situação de maior vulnerabilidade, foi uma solução buscada pelo Ceará para equacionar seus próprios problemas. Ao incentivar a colaboração horizontal, sem conhecimento prévio, o governo estadual acionou estratégia semelhante à adotada por Xangai, na China, como alternativa de melhoria de sua rede (conferir: http:// thelearningcurve.pearson.com/case-studies/article/helping-the-under-performers).

O tempo dirá se os resultados deste processo de colaboração horizontal induzida provocaram os impactos desejados sobre o conjunto da rede escolar. É oportuno registrar, contudo, que, considerando o conhecimento hoje acumulado sobre redes colaborativas, a alternativa encontrada pelo Ceará faz sentido. A ideia de incentivos financeiros para escolas com melhores e piores resultados, porém, esbarra numa questão prática: qual será o espelho para unidades localizadas fora dos extremos e que são a grande maioria? Buscarão chegar ao topo ou, movidas pela inércia, optarão pelo prêmio de consolação dos piores resultados? Os primeiros estudos sobre tais iniciativas, realizados sob os auspícios da Secretaria de Educação do Ceará, indicam que ainda é cedo para se chegar a conclusões sobre a matéria. A indução em si parece ser positiva, mas as formas de implementação, contudo, podem ser aperfeiçoadas. ${ }^{14}$

\section{Afastar-se para se aproximar}

A reconstituição de elementos da trajetória do pacto colaborativo do Ceará permite perceber uma construção histórica e social que adquire nuanças distintas, na medida em que o tempo vai acrescentando novos contornos ao desenho original. A semente da colaboração, nesse sentido, vem de longe e remonta a um momento anterior aos próprios dispositivos legais sobre a matéria, quando era menor o grau de regulamentação e institucionalização.

O jogo passado-presente está em constante movimento, no qual, como num caleidoscópio, as peças se mantêm. A colaboração se materializa num canal de dupla via entre o estado e os municípios, seja sob a forma de cooperação financeira e técnica, ou através de outros mecanismos de implementação das iniciativas perseguidas. O que se percebe ao longo do processo é que a história de colaboração entre estado e municípios no Ceará ocorre num patamar que poderia ser situado para além da política partidária, caracterizando-se como uma construção social marcada por valores culturais e forjada pelas contingências econômicas de um estado pobre, que descobre na união de forças, se não a solução, pelo menos um caminho para se construir. 
Embora possa não ser visível numa análise de superfície, as instâncias regionais exerceram, em diferentes momentos do pacto colaborativo do Ceará, uma mediação e um protagonismo estratégico, atuando como ponte entre as duas esferas públicas aqui consideradas. Há que se registrar também uma peculiaridade na ação dos agentes públicos, atores da concepção e da operacionalização das políticas educacionais, ao concretizar a cooperação. A despeito das diferenças políticas, que em distintos momentos desta construção foram consideráveis, o desejo de somar forças se impôs sobre a divisão.

Se alguma lição pode ser extraída da experiência do Ceará, diríamos que se relaciona a duas coisas. Primeiro, a firmeza de propósitos; segundo, a confiança mútua. Os governos se vão. Os protagonistas mudam. O desafio permanece e é de todos. Se os caminhos não estavam dados na partida, eles foram se esclarecendo na trajetória e na medida em que soluções próprias foram buscadas e encontradas. É verdade que as coisas não se constroem por passe de mágica, nem da noite para o dia, pois "devagar é que o escuro se faz claro". Se tal movimento não é captado a olho nu, é preciso, pois, afastar-se para melhor ver e, assim, se aproximar.

\section{Notas}

1. O termo colaboração, segundo o dicionário Aurélio, é um substantivo feminino, que significa 1. ato ou efeito de colaborar e 2. trabalho feito em comum com uma ou mais pessoas; cooperação, ajuda, auxílio. Já o termo cooperação, também substantivo feminino, significa ato ou efeito de cooperar. A palavra cooperar vem do latim cooperatio,ónis 'auxílio, colaboração'. Neste texto, os dois termos são utilizados de forma indiscriminada.

2. Conferir: Lei n. 16, de 12 de Agosto de 1834. Faz algumas alterações e adições à Constituição Política do Império, nos termos da Lei de 12 de outubro de 1832. Disponível em: <http://www2. camara.leg.br/legin/fed/lei/1824-1899/lei-16-12-agosto-1834-532609-publicacaooriginal-14881-pl. html> Acesso em: 25 nov. 2013.

3. O salário-educação é uma contribuição social prevista pela Constituição Federal (art. 212, § 5º) e regulamentada pelas leis n. 9.424/96, 9.766/98, Decreto n. 6003/2006 e Lei n. 11.457/2007. Destina-se ao financiamento de programas, projetos e ações voltados para o financiamento da educação básica pública, podendo ser aplicada na educação especial, desde que vinculada à educação básica.

4. Para maiores esclarecimentos, conferir, no portal do Ministério da Educação, as diversas iniciativas direcionadas para os municípios.

5. Conferir: <http://arranjoeducacionalpaulista.blogspot.com/>. Acesso em: 29 nov. 2013.

6. Entre maio e agosto de 2013, a Sase realizou três eventos para discutir o tema, um deles em São Paulo (8 e 9 de maio de 2013) e dois outros em Brasília (4 de junho e 26-27 de agosto de 2013).

7. O projeto aprovado na Comissão de Assuntos Econômicos (CAE) do Senado (Substitutivo do relator Senador José Pimentel, 28/05/2013), ao tratar do regime de colaboração "visando ao alcance das metas e à implementação das estratégias objeto" do PNE (art. 7º), prevê que "o fortalecimento do regime de colaboração entre os municípios dar-se-á inclusive mediante a adoção de arranjos de desenvolvimento da educação" (§ 6º. Grifo das autoras).

8. Afirmação feita em meio a um diálogo travado por ocasião de evento realizado por iniciativa da UFPI: II Seminário Nacional de Administração Educacional/Encontro Estadual da Associação 
Nacional de Política e Administração da Educação/Encontro do Programa de Apoio aos Dirigentes Municipais de Educação/Conferência Livre da Conae/2014. Teresina, 27 a 29 de agosto de 2013.

9. A discussão da municipalização se concentra no ensino fundamental, por esta etapa da educação básica ser, conforme preconiza a LDB nos seus artigos 10 e 11, ação compartilhada entre estados e municípios.

10. Considerando que este artigo foi produzido em 2013, portanto, penúltimo ano do segundo governo Cid Gomes, a experiência de colaboração terá 20 anos quando sua gestão for concluída, em 2014.

11. Dados relativos às matrículas do ensino fundamental no Ceará mostram que, no período 19922011, a rede estadual teve seu percentual de atendimento reduzido de $47 \%$ para $7,4 \%$, sendo que, no período $1992-1998$, as matrículas municipais cresceram de $53 \%$ para $68 \%$ do total de matrículas públicas. Nesse mesmo período, portanto, anterior à criação do Fundef, a rede estadual teve um incremento de 65.400 vagas, ao passo que as redes municipais criaram 603.892 novas vagas.

12. No período de vigência do Fundef (1998-2006), as matrículas do ensino fundamental no estado do Ceará se comportaram da seguinte forma: a rede estadual diminuiu 332.722 vagas e as redes municipais cresceram 179.018 vagas. Considerando os dados apresentados na nota 11, é evidente que o crescimento das redes municipais se deu antes mesmo da implantação do Fundef. Importante destacar que, nesse período, o comportamento demográfico da população passou a ter impacto na matrícula do ensino fundamental, iniciando um processo de redução de demanda.

13. Trata-se da vinculação de $18 \%$ do rateio da cota-parte dos municípios nas transferências do Imposto sobre Operações Relativas à Circulação de Mercadorias e sobre Prestações de Serviços de Transporte Interestadual e Intermunicipal e de Comunicação (ICMS), em função de seus resultados na educação (CEARÁ, Lei n. 14.023, de 17 de dezembro de 2007, art. 1º, II).

14. Importante destacar que, embora as escolas envolvidas na amostra da pesquisa pertencessem às redes municipais, o Relatório não enumera nenhum tipo de articulação envolvendo a(s) Secretaria(s) Municipal(is) de Educação (SME), o que impede a compreensão acerca do tipo de colaboração estabelecido entre os dois entes federados. Uma análise mais detalhada e abrangente desta ação demandaria leitura mais pormenorizada de outros documentos que orientam o Prêmio Escola Nota 10.

\section{Referências}

ABRUCIO, F.L. Associativismo territorial para a cooperação intergovernamental. In: ABRUCIO, F.L.; RAMOS, M.N. (Org.). Regime de colaboração e associativismo territorial: arranjos de desenvolvimento da educação. São Paulo: Fundação Santillana, 2012. p. $17-30$.

ARAUJO, G. Federalismo cooperativo e arranjos de desenvolvimento da educação: o atalho silencioso do empresariado para a definição e regulamentação do regime de cooperação. Revista Brasileira de Política e Administração da Educação, v. 28, n. 2, 2012. Disponível em: <http://seer.ufrgs.br/index.php/rbpae/article/view/37419/24160>.

AYED, C.B. As desigualdades socioespaciais de acesso aos saberes: uma perspectiva de renovação da sociologia das desigualdades escolares? Educação \& Sociedade, Campinas, v. 33, n. 120, p. 783-803, 2012.

BACELAR, T. Globalização e território. 2008a. Disponível em: <http://blogs.unigranrio. com. br/enade/files/2010/06/globalizacao-e-territorio.pdf> Acesso em: 14 set. 2013. 
BACELAR, T. Política pública, participação social, desenvolvimento sustentável e territórios. In: MIRANDA, C.; TIBURCIO, B. (Org.). Articulação de políticas públicas e atores sociais. Brasília, DF: IICA, 2008b. v. 8.

BRASIL. MEC. INEP. Censo Escolar 2011. Disponível em: <http://portal.inep.gov.br/ basica-censo-escolar-sinopse-sinopse>. Acesso em: 2 jul. 2013.

BRASIL. MEC. SASE. Portaria n. 1.238, de 11 de outubro de 2012. Constitui Grupo de Trabalho para elaborar estudos sobre a implementação de regime de colaboração mediante Arranjos de Desenvolvimento da Educação.

BRASIL. MEC. CNE. CEB. Resolução n. 1, de 23 de janeiro de 2012. Dispõe sobre a implementação do regime de colaboração mediante Arranjo de Desenvolvimento da Educação (ADE), como instrumento de gestão pública para a melhoria da qualidade social da educação.

BRASIL. Parecer CNE/CEB n. 9/2011. Análise de proposta de fortalecimento e implementação do regime de colaboração mediante arranjos de desenvolvimento da educação. Parecer Homologado Despacho do Ministro. Diário Oficial da União, Brasília, DF, Seção 1, p. 2322, nov. 2011.

BRASIL. Presidência da República. Casa Civil. Subchefia para Assuntos Jurídicos. Constituição da República Federativa do Brasil de 1988. Disponível em: <http://www. planalto.gov.br/ ccivil_03/constituicao/constituicao.htm>. Acesso em: 7 set. 2013.

BRASIL Lei n. 9394, de 20 de dezembro de 1996. Estabelece as diretrizes e bases da educação nacional. Disponível em: <http://www.planalto.gov.br/ccivil_03/ leis/19394.htm>. Acesso em: 7 set. 2013.

BRASIL Lei n. 9424, de 24 de dezembro de 1996. Dispõe sobre o Fundo de Manutenção e Desenvolvimento do Ensino Fundamental e de Valorização do Magistério, na forma prevista no art. 60, § 7º , do Ato das Disposições Constitucionais Transitórias, e dá outras providências. Disponível em: <http://www.planalto.gov.br/ ccivil_03/leis/ 19424.htm>. Acesso em: 7 set. 2013.

BRASIL. Lei n. 11.107, de 6 de abril de 2005. Dispõe sobre normas gerais de contratação de consórcios públicos e dá outras providências. Disponível em: <http://www. planalto.gov.br/ccivil_03/_ato2004-2006/2005/Lei/L11107.htm>. Acesso em: 9 set. 2013.

BRASIL. Lei n. 11.494, de 20 de junho de 2007. Regulamenta o Fundo de Manutenção e Desenvolvimento da Educação Básica e de Valorização dos Profissionais da Educação - Fundeb, de que trata o art. 60 do Ato das Disposições Constitucionais Transitórias; altera a Lei n. 10.195, de 14 de fevereiro de 2001; revoga dispositivos das Leis n. 9.424, de 24 de dezembro de 1996, 10.880, de 9 de junho de 2004, e 10.845, de 5 de março 
de 2004; e dá outras providências. Disponível em: <http://www.planalto.gov.br/ ccivil_03/_ato2007-2010/2007/Lei/L11494.htm>. Acesso em: 7 set. 2013.

CEARÁ. Lei n. 14.023, de 17 de dezembro de 2007. Modifica dispositivos da Lei n. 12.612, de 7 de agosto de 1996, que define critérios para distribuição da parcela de receita do produto e arrecadação do Imposto sobre Operações Relativas à Circulação de Mercadorias e sobre Prestações de Serviços de Transporte Interestadual e Intermunicipal e de Comunicação - ICMS, pertencente aos municípios, e dá outras providências. D.O.E, 19 dez. 2007. Disponível em: <http://www.fortaleza.ce.gov.br/ emlurb/lei-no-14023-de-17-de-dezembro-de-2007>. Acesso em: 17 set. 2013.

CEARÁ. Lei n. 14.026, de 17 de dezembro de 2007. Cria o Programa Alfabetização na Idade Certa - Paic, de cooperação técnica e incentivo para melhoria dos indicadores de aprendizagem nos municípios cearenses, e dá outras providências. D.O.E., 19 dez. 2007. Disponível em: <http://www.al.ce.gov.br/ legislativo/legislacao5/ leis2007/14026.htm>. Acesso em: 14 set. 2013.

CEARÁ. Lei n. 14.371, de 19 de junho de 2009. Cria o Prêmio Escola Nota Dez, destinado a premiar as escolas públicas com melhor resultado no Índice de Desempenho Escolar-Alfabetização (IDE-Alfa), e dá outras providencias. D.O.E., 19 jun. 2009. Disponível em: <http://www.al.ce.gov.br/ legislativo/legislacao5/leis2009/14371.htm>. Acesso em: 14 set. 2013.

CEARÁ. Lei n. 15.052, de 6 de dezembro de 2011. Institui o Prêmio Escola Nota Dez, destinado a premiar as escolas públicas com melhores resultados de aprendizagem no segundo e quinto anos de ensino fundamental, e dá outras providências. D.O.E., 12 dez. 2011. Disponível em: <http://www.al.ce.gov.br/legislativo/legislacao5/leis2011/15052. htm>. Acesso em: 14 set. 2013.

CENPEC. Educação em territórios de alta vulnerabilidade social na metrópole - Síntese das conclusões. São Paulo, 2011. Disponível em: <http://www.cenpec.org.br/biblioteca/ educacao/producoes-cenpec/educacao-em-territorios-de-alta-vulnerabilidade-socialna-metropole>. Acesso em: 29 nov. 2013.

GRACINDO, R.V. O escrito, o dito e o feito: educação e partidos políticos. Campinas: Papirus, 1994.

GUIMARÃES ROSA, J. Ave Palavra. Ficção completa. v. 1. Rio de Janeiro: Nova Aguilar, 1994. p. 989.

GUIMARÃES ROSA, J. Sagarana. Ficção completa. v. 1. Rio de Janeiro: Nova Aguilar, 1994.

KOSLINSKI, M.C.; ALVES, F. Novos olhares para as desigualdades de oportunidades 
educacionais: a segregação residencial e a relação favela-asfalto no contexto carioca. Educação \& Sociedade, Campinas, v. 33, n. 120, p. 805-831, 2012.

MENDES, C.M.S. A descentralização do ensino fundamental no Ceará. Fortaleza: Editora da Inesp, 2002.

OLIVEIRA, R.P.; SANTANA, W. Educação e federalismo no Brasil: combater as desigualdades, garantir a diversidade. Brasília, DF: Unesco, 2010. p. 9-35; p. 287-295.

PEARSON. "Helping the under-performers". The learning curve. The Economist, London, 2012. Disponível em: <http://thelearningcurve.pearson.com/case-studies/ article/helping-the-under-performers> Acesso em: 14 set. 2013.

RIBEIRO, E.C.M.; SILVA, M.M.C. Um retrato do semiárido cearense. Texto para Discussão, Fortaleza, n. 76, 2010. Disponível em: <http://www.ipece.ce.gov.br/ publicacoes/ textos_discussao/TD_76.pdf>. Acesso em: 14 set. 2013.

SEDUC. Pesquisa de Boas Práticas 2011: análise de fatores de alto desempenho e boas práticas em escolas da rede pública do estado do Ceará. Adolfo Ignacio Calderón (redação e responsável técnico). Ceará: Seduc, s./d. (Arquivo em pdf).

SENADO FEDERAL. Projeto de Lei da Câmara n. 103, de 2012 (PL n. 8.035/2010 na Casa de origem) (De iniciativa da Presidência da República). Aprova o Plano Nacional da Educação - PNE e dá outras providencias. Disponível em: <http://www.senado.gov. br/atividade/ materia/getPDF.asp?t=115871\&tp=1> Acesso em: 7 set. 2013.

VERAS, M.E.B. Estado e financiamento da educação no Ceará. 1990. Dissertação (mestrado em Educação Brasileira) - Universidade Federal do Ceará. Fortaleza.

VIEIRA, S.L. Educação básica no Ceará: construindo um pacto colaborativo. In: OLIVEIRA, R.P; SANTANA, W. Educação e federalismo no Brasil: combater as desigualdades, garantir a diversidade. Brasília, DF: Unesco, 2010. p. 271-286.

OLIVEIRA, R.P; SANTANA, W. Gestão, avaliação e sucesso escolar: recortes da trajetória cearense. Estudos Avançados, São Paulo, v. 21, n. 60, p. 45-60, 2007b.

Recebido em 3 outubro de 2013.

Aprovado em 2 de dezembro de 2013. 
